\title{
Characterising the Progress of Gelation in Tofu Making with Ohmic Heating
}

\author{
Cheng-Chang Lien1, Ching-Hua Ting2,3* \\ ${ }^{1}$ Department of Biomechatronic Engineering, National Chiayi University, Chiayi, Taiwan \\ ${ }^{2}$ Department of Mechanical and Energy Engineering, National Chiayi University, Chiayi, Taiwan \\ ${ }^{3}$ Center of Energy and Sensor Technology, National Chiayi University, Chiayi, Taiwan \\ Email: ${ }^{*}$ cting@mail.ncyu.edu.tw
}

Received December 2014

\begin{abstract}
In tofu making by heat treatment, the addition of coagulant ionizes the proteins as a result of heat dissolution and the ionized proteins aggregate with the coagulant to form protein clusters. The electrical conductivity (EC) of the soya milk emulsion varies in response to the progress of gelation. By ohmic heating, the applied current and voltage directly indicate the electrical conductivity of the soya milk emulsion and then indirectly the progress of tofu gelation. In this paper, ultrasonic measurement is adopted to explore the feasibility of using EC as an indicator of tofu gelation. Experiments showed a strong correlation between EC and ultrasonic measurement in characterisation of tofu gelation.
\end{abstract}

\section{Keywords}

Ohmic Heating, Electrical Conductivity, Ultrasound, Gelation

\section{Introduction}

Tofu is a salt- or acid-coagulated water-based gel, with soya lipids and proteins as well as other constituents trapped in gel networks [1]. It is rich in proteins and isoflavones and has a notable name "meat from the soil". It is made by coagulating soya milk-followed by either pressure or heat treatment after the addition of a coagulant. The taste of tofu is significantly affected by its final texture [2], i.e., by the firmness of the tofu gel's structure. The textural property is determined by the concentration of soya milk, the type and concentration of coagulant, the gelating pressure and temperature, and the gelation time [3].

The quality of a tofu can be examined using destructive testing. A textural analyzer is suitable for characterizing the mechanical property; while microscope analysis explores the chemical composition and the microstructure [4] [5]. The above two methods are of a destructive nature and require laboratory practice. They are not suitable for on-line application as a quality indicator. Ultrasound which can give a big amount of information in a short time [6] has been shown to be effective in detecting the gelation process and the final product in an efficient way [3] [5]. While ultrasound is a means feasible for on-line quality detection, its setup is expensive.

"Corresponding author. 
The formation of a tofu gel requires soya milk mixed with a coagulant to be heated to a reaction temperature. In gelation, protein clusters are formed as a mechanism of ion exchanging between soya milk and the added coagulant. The concentration of the exchanging ions, anions orcations, is a result of the ongoing gelation process. The ion concentration can be easily characterized as electrical conductivity, an easy, economic, and efficient measurement [7]. Adequate temperature rising rates of soya milk is controllable by application of different voltages onto the soya milk. The temperature profile can be used in tofu making with heat treatment and the electrical conductivity response can be for monitoring of gelation [8].

The objective of this study is to explore the feasibility of using EC in ohmic heating as a gelation indicator of tofu making. Ultrasonic measurements are used as a reference for calibrating EC measurements.

\section{Materials and Methods}

\subsection{Materials}

Washed soya beans $(800 \mathrm{~g})$ were soaked for 8 - 12 hrs at a constant temperature $\left(30^{\circ} \mathrm{C}\right)$ in reverse osmosis (RO) water. One time by weight of RO water was added to the equivalent dry weight of the soya beans. The mixtures were ground and centrifugally filtered for 2 min to remove the residue. The soya milk produce was adjusted to a concentration of $10^{\circ}$ Brix. The procedure of preparing soya milk is summarized as Figure 1.

\subsection{Ohmic Heating in Tofu Making}

The performance of ohmic heating in food processing depends on the electrical conductivity of the foodstuff. An electrical current flowing through the foodstuff has power conduction by the moving ions in the foodstuff fluid. The viscosity of the fluid decreases in response to a hotter fluid. This speeds up the ionic motion and hence the electrical conductivity. The food fluid consists of conductive and resistive components which in turn, convert the electric current into heat [9] [10].

Addition of a coagulant into heated soya milk triggers the formation of tofu gels. The formation is a two-step mechanism [1]: soya proteins are denatured and then aggregated by the coagulant. Soya beans contain $35 \%-40 \%$ of storage and whey proteins by weight. The 7S protein, conglycinin, and 11S protein, glycinin, are the two major proteins that construct the property of a tofu produce [11].

Figure 2 depicts the mechanism of soya milk transforming to tofu gels. When soya milk is heated to $65^{\circ} \mathrm{C}$ and beyond, the oil body is released. This is the first step of transformation. The 7S and 11S proteins will escape from the subunits at $75^{\circ} \mathrm{C}$ and $80^{\circ} \mathrm{C}$, respectively. Subunits are surrounded by protein particles with a size of 100 $\mathrm{nm}[11]-[13]$. The transformation completes.

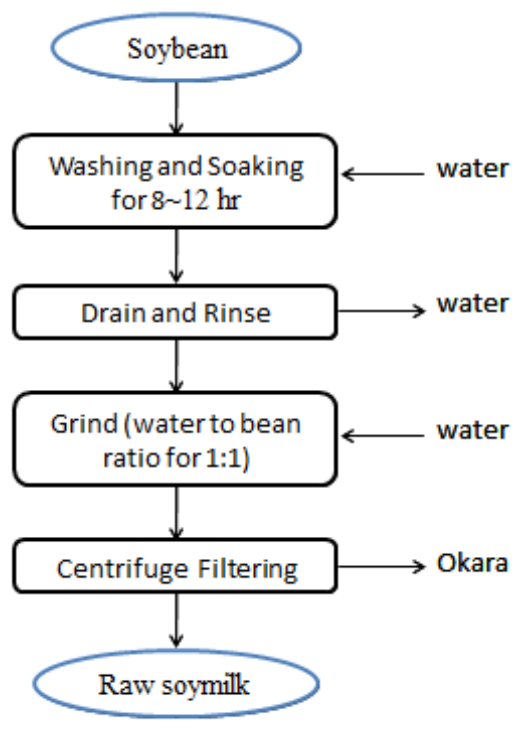

Figure 1. Procedure of soya milk preparation. 


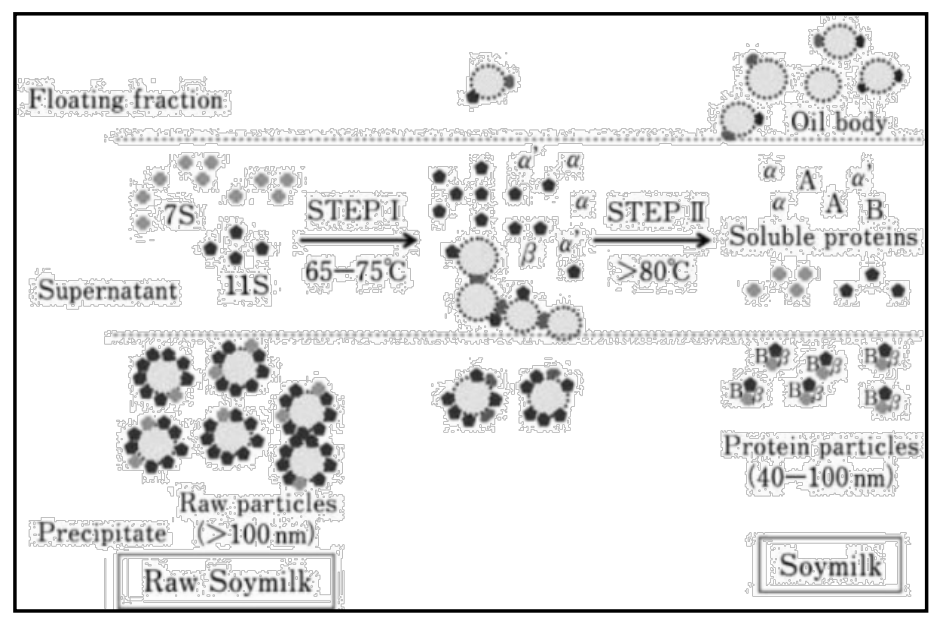

Figure 2. Process of protein separation in heated soya milk [11].

The process of tofu coagulation by ohmic heating is graphically illustrated in Figure 3. The ions become a good conductor to the impinging current in ohmic heating and the milk is therefore heated up by the current. Ions dissolve in the milk uniformly. Hence the milk will have a homogeneous temperature distribution in the whole volume.

\subsection{Circuitry Model of Ohmic Heating}

Figure 4 presents ohmic heating in soya milk as a circuitry model. The resistance $R$ characterizes the intrinsic electrical conductivity of the soya milk and the capacitance $C$ describes the capacitive effect built by the two electrode plates with the soya milk as the electrolyte in between. The circuit has the following first-order dynamics:

$$
I=\frac{V}{R}+C \frac{d v}{d t}
$$

The capacitive effect is transient. In theory, it becomes a barrier to DC (direct current) power and energy storage to alternate current (AC).

While the temperature of the soya milk increases, the electrical conductivity of the soya milk increases in a positive trend as a result of more ionized subunits [1] [11]-[12]:

$$
\sigma_{T}=\sigma_{\text {ref }} \cdot\left[1+m \cdot\left(T-T_{\text {ref }}\right)\right]
$$

where $\sigma_{T}$ is the electrical conductivity at current temperature $T$ and $\sigma_{r e f}$ is the electrical conductivity at the reference temperature $T_{\text {ref }}$. Ions in an electrolyte are easily to escape from the substance molecules at a hot atmosphere. Different substances will have different properties and hence the $\sigma_{T}$ is substance-specific [10] [14].

\subsection{Experimental Rigs and Procedures}

The setup for ohmic heating experiments and ultrasonic measurement is shown in Figure 5. Readers are referred to [3] for details of ultrasonic measurements. Soya milk is placed in a steel container $\left(\mathrm{L} \times \mathrm{W}: 11 \times 7 \mathrm{~cm}^{2}\right)$ with ceramic coating. The two titanium electrodes are powered with an AC/DC power supply (APS-1102, Instek, Taiwan) which is remotely controlled by a computer using the LabVIEW software (V8.3, National Instrument, USA). The temperature of the soya milk is detected using a TM-925 temperature transducer (Prosperous, Taiwan).

A $1 \mathrm{MHz}$ ultrasonic transducer (WesternNDE, Canada) is mounted onto the sample chamber. A computercontrolled ultrasonic instrument (WT-UT-001A, Western NDE, Canada) excites the transducer to emit a chirp of ultrasound waves into the chamber, amplifies the received ultrasound waves at a gain of $60 \mathrm{~dB}$, and acquires responsive waveforms at a sampling frequency of $100 \mathrm{MHz}$. Ultrasonic responses and inferred data are displayed on-line for visual inspection and recorded for subsequent off-line analysis. The transducer was calibrated 


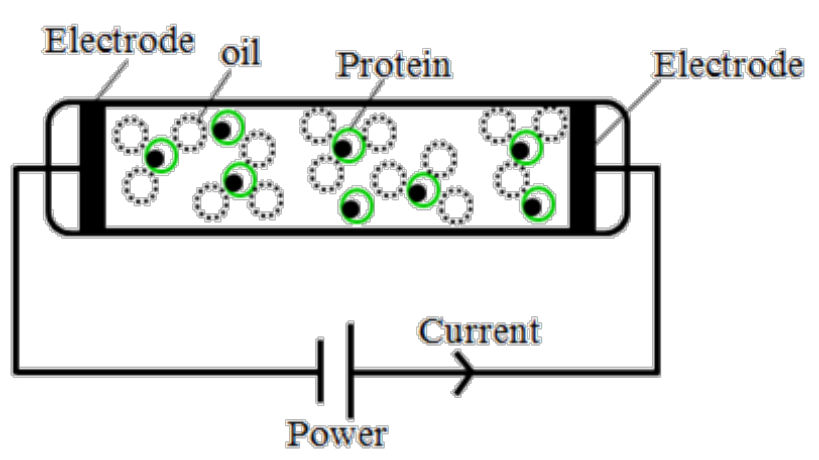

Figure 3. Soya milk under ohmic heating [13].

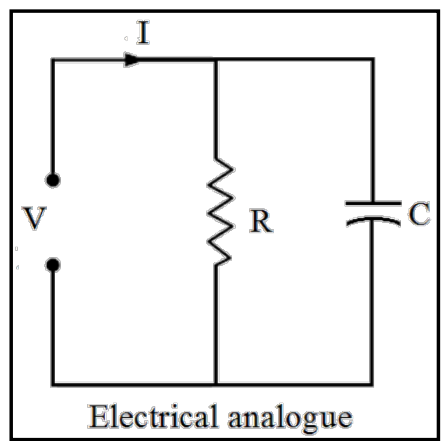

Figure 4. Equivalent circuit model of ohmic heating.

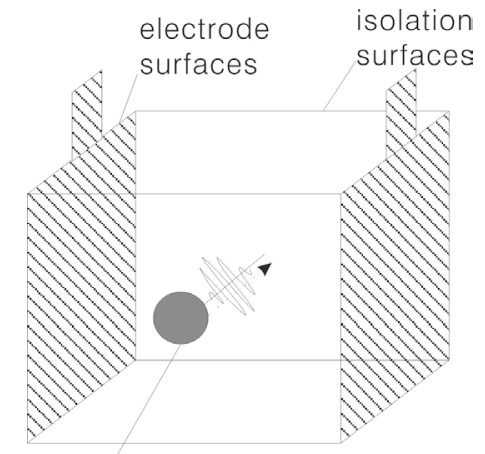

ultrasound transduseer

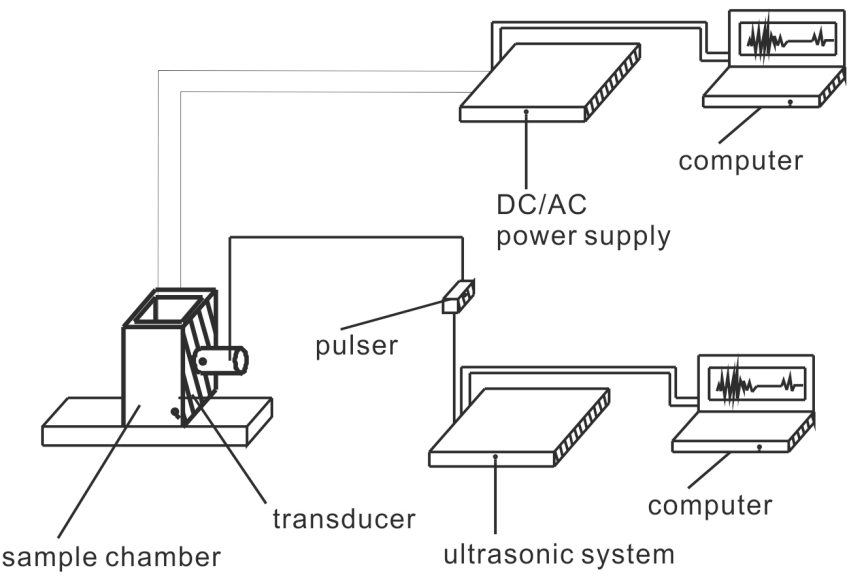

Figure 5. The experimental setup. 
with RO water as the reference medium.

\section{Results and Discussion}

\subsection{Ultrasonic Characteristics of Ohmic Heating}

In theory, the velocity of an ultrasound wave travelling in a medium is determined by:

$$
c=\sqrt{\frac{E}{\rho}}
$$

where $E$ is the elastic modulus and $\rho$ the density of the milk. The modulus of elasticity increasing as a function of time in coagulating tofu gels and should, according to the above equation, increase the velocity.

Figure 6 shows ultrasonic measurements of ultrasound waves travel in coagulating tofu gels under traditional heat treatment [3]. Its velocity profile is contradictory to the above statement. This is because, in traditional heat treatment, the formation of tofu gels (clusters and air bubbles) alters the molecular structure and intermolecular interactions [4] and hence the elasticity changes in a dramatic degree because of the presence of airbubbles.

Figure 7 show ultrasonic velocity measurements under ohmic heating, which have totally contradictory profiles to Figure 6. There is no doubt that the soya tofu gels are in a liquid state at the beginning of coagulation. But in the course of ohmic heating more protein clusters aggregate probably in a homogeneous way and hence the elastic modulus of tofu gels strengthens. The homogeneous coagulation comes from that the electrical current of ohmic heating can penetrate every protein in the soya milk and hence all proteins could have the same intense of ionisation. This homogeneity of protein ionisation is unlikely to occur in traditional heat treatment that heats the soya milk through non-uniform heat convection.

\subsection{Characterisation by Electrical Conductivity}

Figure 8 shows electrical conductivities of 4 tofu gels with different concentrations of coagulant. The EC measurement has first-order dynamics. This behaviour is identical to that of ultrasonic velocity and attenuation. The denser the coagulant is the higher the electrical conductivity. The EC is low in the beginning of ohmic heating and nearly saturates in steady state.

\section{Conclusion}

In this paper, we have presented the potential application of combing ohmic heating and associated electrical conductivity measurement in tofu making by heat treatment. In theory, the soya milk can be uniformly cooked

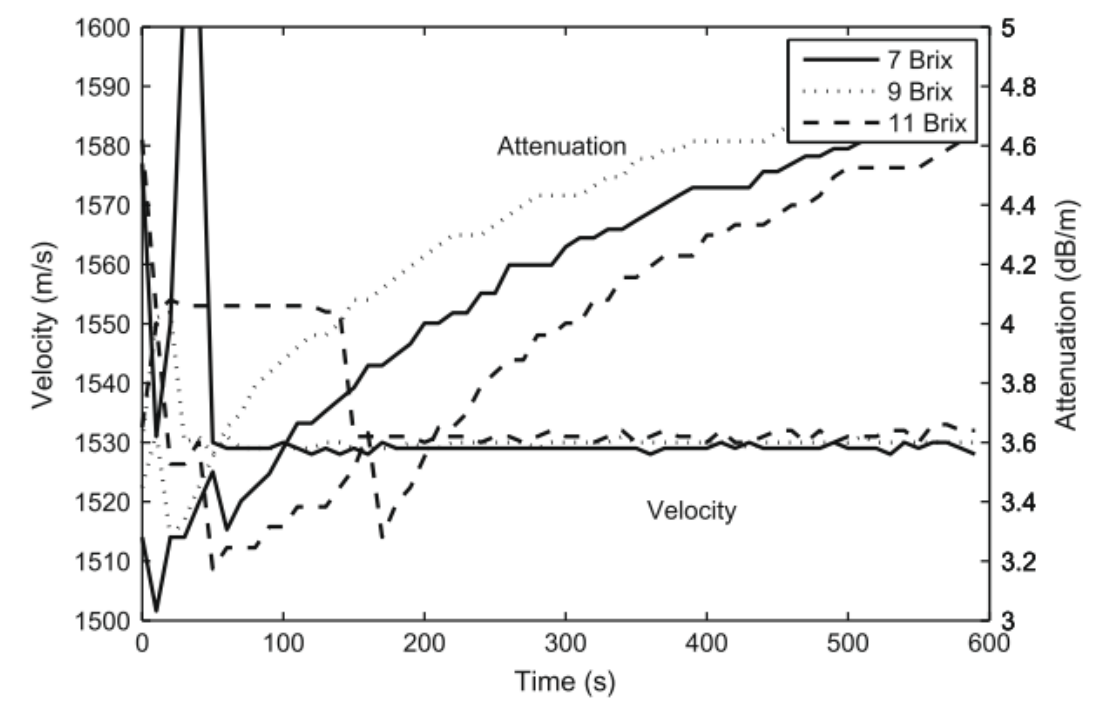

Figure 6. Ultrasonic measurements of coagulating tofu gelsunder traditional heat treatment [3]: calcium sulphate, $1.0 \% \mathrm{w} / \mathrm{w}$; induction temperature, $75^{\circ} \mathrm{C}$. 


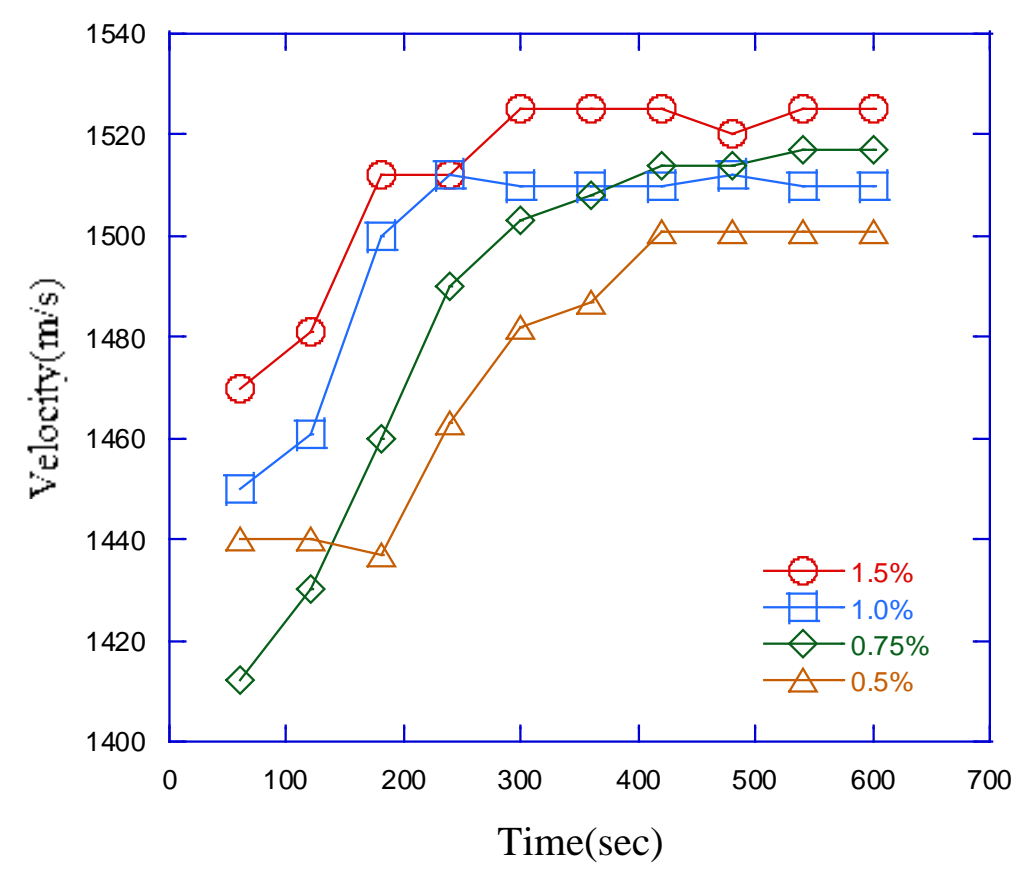

Figure 7. Ultrasonic measurements of coagulating tofu gels under ohmic heating: calcium sulphate; soya milk, $10^{\circ}$ Brix; induction temperature, $90^{\circ} \mathrm{C}$.

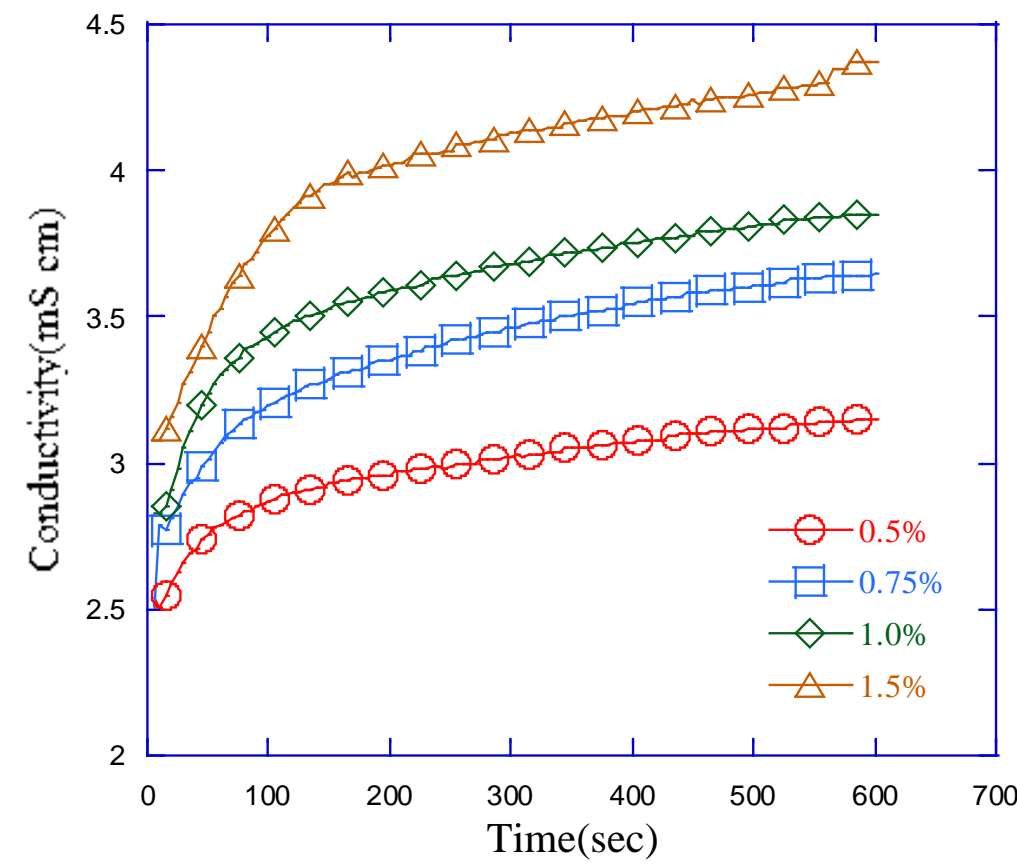

Figure 8. EC measurements of coagulating tofu gels under ohmic heating: calcium sulphate; soya milk, $10^{\circ}$ Brix; induction temperature, $90^{\circ} \mathrm{C}$.

By ohmic heating and leads to tofu gels with a homogeneous structure. The homogeneity is unveiled by ultrasonic velocity measurement. Ultrasonic measurement gives reliable, on-line indication of tofu gelation dynamics. However, the instalment of an ultrasonic measurement system is costly. EC measurement from ohmic heating can be an affordable gelation indicator. Hence the electrical conductivity measurement could be a fast, convenient, and non-destructive testing method for on-line indication of tofu quality. 


\section{Acknowledgements}

This work was financially supported by the National Science Council of Taiwan under the Grant No. 102-2221E-415-010.

\section{References}

[1] Kohyama, K., Sano, Y. and Doi, E. (1995) Rheological Characteristics and Gelation Mechanism of Tofu (Soybean Crud). Journal of Agricultural and Food Chemistry, 43, 1808-1812. http://dx.doi.org/10.1021/jf00055a011

[2] Jackson,C.-J., Dini, J.P., Lavandier, C., Rupasinghe, H.P.V., Faulkner, H., Poysa, V., Buzzell, D. and DeGrandis, S. (2002) Effects of Processing on the Content and Composition of Isoflavones during Manufacturing of Soy Beverage and Tofu. Seminars in Food Analysis, 37, 1117-1123.

[3] Ting, C.H., Kuo, F.J., Lien, C.C. and Sheng, C.T. (2009) Use of Ultrasound for Characterising the Gelation Process in Heat Induced $\mathrm{CaSO}_{4}-2 \mathrm{H}_{2} \mathrm{O}$ Tofu Curd. Journal of Food Engineering, 93, 101-107. http://dx.doi.org/10.1016/j.jfoodeng.2009.01.015

[4] Saowapark, S., Apichartsrangkoon, A. and Bell, A.E. (2008) Viscoelastic Properties of High Pressure and Heat Induced Tofu Gels. Food Chemistry, 107, 984-989.

[5] Kuo, F.J., Lien, C.C., Huang, Y.Y., and Ting, C.H. (2011) Use of Ultrasound for Measuring Tofu Texture. Journal of Engineering in Agriculture, Environment and Food, 4, 83-89. http://dx.doi.org/10.1016/S1881-8366(11)80017-0

[6] Awad, T.S., Moharram, H.A., Shaltout, O.E., Asker, D. and Youssef, M.M. (2012) Applications of Ultrasound in Analysis, Processing and Quality Control of Food: A Review. Food Research International, 48, 410-427. http://dx.doi.org/10.1016/j.foodres.2012.05.004

[7] Vicente, A.A. (2007) Ohmic Heating as an Alternative to Conventional Thermal Treatment. Dissertation for PhD Degree in Chemical and Biological Engineering, Universidade do Minho Escola de Engenharia.

[8] Lien, C.C., Shen, Y.C. and Ting, C.H. (2014) Ohmic Heating for Tofu Making-A Pilot Study. Journal of Agricultural Chemistry and Environment, 3, 7-13. http://dx.doi.org/10.4236/jacen.2014.32B002

[9] Amatore, C., Berthou, M. and Héert, S. (1998) Fundamental Principles of Electrochemical Ohmic Heating of Solutions. Journal of Electroanalytical Chemistry, 457, 191-203. http://dx.doi.org/10.1016/S0022-0728(98)00306-4

[10] Stanc, J. and Zitny, R. (2010) Milk Fouling at Direct Ohmic Heating. Journal of Food Engineering, 99, 437-444. http://dx.doi.org/10.1016/j.jfoodeng.2009.11.019

[11] Ono, T., Tezuka, M., Taira, H., Igarashi, Y. and Yagasaki, K. (2000) Properties of Tofus and Soy Milks Prepared from Soybeans Having Different Subunits of Glycinin. Journal of Agricultural and Food Chemistry, 48, 1111-1117. http://dx.doi.org/10.1021/jf9905601

[12] Guo, S.T., and Ono, T. (2005) The Role of Composition and Content of Protein Particles in Soymilk on Tofu Curding by Glucono- $\delta$-Lactone or Calcium Sulfate. Journal of Food Science, 70, C258-C262. http://dx.doi.org/10.1111/j.1365-2621.2005.tb07170.x

[13] Li, X., Toyoda, K. and Ihara, I. (2011) Coagulation Process of Soymilk Characterized by Electrical Impedance Spectroscopy. Journal of Food Engineering, 105, 563-568. http://dx.doi.org/10.1016/j.jfoodeng.2011.03.023

[14] Sastry, S.K., Sarang, S. and Knipe, L. (2008) Electrical Conductivity of Fruits and Meats during Ohmic Heating. Journal of Food Engineering, 87, 351-356. http://dx.doi.org/10.1016/j.jfoodeng.2007.12.012 